\title{
A Predictive Model To Describe the Effects of Temperature, Sodium Lactate, and Sodium Diacetate on the Inactivation of a Serotype 4b Strain of Listeria monocytogenes in a Frankfurter Slurry
}

\author{
K. K. SCHULTZE, ${ }^{1}$ R. H. LINTON, ${ }^{1 *}$ M. A. COUSIN, ${ }^{1}$ J. B. LUCHANSKY, ${ }^{2}$ AND M. L. TAMPLIN ${ }^{2}$
}

\begin{abstract}
${ }^{1}$ Department of Food Science, Purdue University, 745 Agriculture Mall Drive, West Lafayette, Indiana 47906; and ${ }^{2}$ U.S. Department of Agriculture, Agricultural Research Service, Microbial Food Safety Research Unit, Eastern Regional Research Center, 600 East Mermaid Lane, Wyndmoor, Pennsylvania 19038, USA
\end{abstract}

MS 05-574: Received 15 November 2005/Accepted 10 February 2006

\begin{abstract}
A modified Gompertz equation was used to model the effects of temperature $\left(55,60\right.$, and $\left.65^{\circ} \mathrm{C}\right)$, sodium lactate $(0,2.4$, and $4.8 \%$ ), and sodium diacetate $(0,0.125$, and $0.25 \%$ ) on inactivation of Listeria monocytogenes strain MFS 102 (serotype $4 \mathrm{~b}$ ) in frankfurter slurry. The effects of these factors were determined on the shouldering region (parameter $A$ ), maximum death rate (parameter $B$ ), and tailing region (parameter $C$ ) of microbial inactivation curves. Increased temperature or sodium diacetate concentrations increased the death rate, whereas increased sodium lactate concentrations decreased heat resistance. Complex two-way interactive effects were also observed. As both temperature and sodium lactate increased, the death rate decreased; however, as temperature and sodium diacetate increased, the death rate increased. The effect of the interaction between sodium lactate and sodium diacetate on the maximum death rate varied with temperature. Increases in both acidulants at temperatures above $56.7^{\circ} \mathrm{C}$ decreased the death rate, whereas at temperatures below $56.7^{\circ} \mathrm{C}$, increases in both acidulants increased the death rate. To test for significant differences between treatments, $D$-values were calculated and compared. This comparison revealed that, in general, sodium lactate increased heat resistance and sodium diacetate decreased heat resistance of L. monocytogenes. This information is important for reducing and minimizing contamination during postprocessing thermal treatments.
\end{abstract}

Listeria monocytogenes (LM) is responsible for approximately 2,500 cases of listeriosis and 500 deaths in the United States each year $(5,13)$. LM is a foodborne pathogen of concern because of the high death rate $(20 \%)$ associated with LM infection and the ability of LM to target particular subsets of the population and to grow under refrigerated food storage conditions (6). In 2003, an LM risk assessment for ready-to-eat (RTE) foods was published by the U.S. Food and Drug Administration (FDA), U.S. Department of Agriculture Food Safety and Inspection Service (USDA-FSIS), and the Centers for Disease Control and Prevention (CDC) (17). According to the assessment, consumption of deli meats and frankfurters (not reheated) is associated with the highest risk of contracting listeriosis on a per serving and per annum basis (17). The presence of LM in RTE foods often is associated with environmental contamination in the postlethality processing and/or packaging area. In RTE food products, postprocessing heat pasteurization can be used to reduce or eliminate LM from product surfaces and/or acidulants can be added to the product formulations to prevent growth of any LM survivors over the shelf life of the product (16).

The addition of lactate and diacetate salts to product

* Author for correspondence. Tel: 765-494-6481; Fax: 765-494-7953;

E-mail: linton@purdue.edu. formulations has been successful in controlling the growth of LM during product shelf life $(7,11)$; however, the effects of these two food grade chemicals, which are generally recognized as safe and can be used together, on the heat resistance of LM have not been well studied, especially at postprocessing pasteurization temperatures. Sodium lactate (0 to $4.8 \%$ ) in minced beef reduced LM heat resistance (12), but an increase in heat resistance was seen in poultry meat (14) and ground beef (8) at the same concentrations. Juneja (8) found that addition of sodium diacetate ( 0 to $0.25 \%$ ) to ground beef reduced the protective effect of sodium lactate (0 to $4.8 \%$ ), thus decreasing the $D$-values (for 60 to $73.9^{\circ} \mathrm{C}$ ). The interactive effects of lactates and diacetates on heat resistance of LM in RTE foods, including frankfurters, have not been studied to any extent.

Predictive models can be useful tools for studying the effects of numerous variables on growth and thermal inactivation kinetics of pathogens in synthetic media and in foods. These models are placed into databases (e.g., ComBase) and in modeling software packages (e.g., the Pathogen Modeling Program) where they can be accessed by food industry professionals and used to determine either how microorganisms grow or the impact of lethality treatments on microbial inactivation for various food products (1). Several mathematical equations have been used to describe the death of pathogens in both laboratory media and 
food systems. The modified Gompertz equation, in combination with polynomial expressions, has been used successfully and was selected for this study because this approach can predict single factor and interactive effects on thermal inactivation $(3,4,9,10)$. The Gompertz equation is also useful for modeling many different types of microbial survival curves, including those with shoulder and tailing regions (9).

The objectives of this study were to (i) develop a predictive model from the modified Gompertz equation based on the effects of temperature, sodium lactate, and sodium diacetate on the inactivation of LM in a frankfurter system and (ii) study the single and interactive effects of the acidulant salts on thermal inactivation at postprocessing pasteurization temperatures.

\section{MATERIALS AND METHODS}

Bacterial strains. LM strain MFS 102 (CDC strain H7776, a Bil-Mar outbreak isolate) (2) was obtained from the culture repository of the Microbial Food Safety Research Unit of the USDA Eastern Regional Research Center (Wyndmoor, Pa.) and was maintained on tryptic soy agar (Becton Dickinson, Sparks, Md.) with $0.6 \%$ (6 g/liter) yeast extract (TSAYE; Becton Dickinson) slants at $7^{\circ} \mathrm{C}$. Before selection of this particular strain, several other strains of LM were screened for heat resistance and recovery in frankfurter slurry. MFS 102 had very high heat resistance and was easily recovered after heating.

A loopful of culture was transferred to $10 \mathrm{ml}$ of sterile tryptic soy broth with yeast extract (TSBYE; Becton Dickinson) and incubated at $37^{\circ} \mathrm{C}$ for $24 \mathrm{~h}$. Culture aliquots $(0.1 \mathrm{ml})$ were again individually transferred into $10 \mathrm{ml}$ of sterile TSBYE and incubated at $37^{\circ} \mathrm{C}$ for $18 \mathrm{~h}$ on a shaker at $100 \mathrm{rpm}$ to create a starting population of $\sim 10^{9} \mathrm{CFU} / \mathrm{ml}$.

Preparation of frankfurter slurry. Reduced-fat all-beef frankfurters from a single lot were obtained directly from a local meat processor and stored at $-18^{\circ} \mathrm{C}$ until used. Packages were thawed overnight at $7^{\circ} \mathrm{C}$ before creating frankfurter slurries. A base formulation $(0 \%$ [ $0 \mathrm{~g} / \mathrm{liter}]$ lactate and $0 \%$ [0 g/liter] diacetate) was developed first to create a uniform slurry before addition of the acidulant salts. The base formulation was created by blending $400 \mathrm{ml}$ of distilled water and $100 \mathrm{~g}$ of frankfurter for $1 \mathrm{~min}$ at high speed (model 51BL32 blender, Waring, New Hartford, Conn.). Thirty grams of refined lecithin (Alfa Aesar, Ward Hill, Mass.) was added to stabilize the emulsion before blending for an additional 2 to $3 \mathrm{~min}$ at high speed. The base formulation was thoroughly mixed and divided into nine equal fractions. Different combinations of sodium lactate $(0,2.4$, or $4.8 \%$, equivalent to 0 , 24 , or $48 \mathrm{~g} /$ liter, respectively) and sodium diacetate $(0,0.125$, $0.25 \%$, equivalent to $0,1.25$, or $2.5 \mathrm{~g} /$ liter, respectively) were added to each fraction (wt/vol) and mixed thoroughly with an aseptic paddle to create the nine different formulations. The slurries were then autoclaved at $121^{\circ} \mathrm{C}$ for $30 \mathrm{~min}$. Before the thermal treatments, the $\mathrm{pH}$ of each slurry $(25 \mathrm{ml})$ was determined (AR15 $\mathrm{pH}$ meter, Accumet Research, Fisher Scientific Company, Pittsburgh, Pa.).

Thermal treatment. A circulating water bath (built by the research team) described by Chhabra et al. (3) was used for thermal inactivation studies. Ninety-nine milliliters of frankfurter slurry was added to two-neck round-bottom 250 -ml glass flasks submerged in a heated water bath. A magnetic stirring bar was placed into each flask to distribute heat evenly throughout the medium.
A standardized thermometer was placed into the neck of one of the flasks to monitor temperature, and the other neck openings were covered with sterile aluminum foil. Once the temperature equilibrated (at 55,60 , or $65^{\circ} \mathrm{C}$ ), $1 \mathrm{ml}$ of the culture was added to the circulating medium (1:100 dilution in cell level); this moment was designated as time 0 . Samples $(1 \mathrm{ml})$ were withdrawn at various intervals, with shorter intervals for treatments at higher temperatures. The treatment temperatures were selected as potential temperatures that could be used for production of RTE meat products without dramatically affecting quality (i.e., without creating purge).

The starting LM population of cells in the thermal treatment experiments at time 0 was determined by adding $1 \mathrm{ml}$ of the culture to dilution bottles containing $99 \mathrm{ml}$ of the appropriate frankfurter slurry formulation. A 1-ml sample was transferred into $9 \mathrm{ml}$ of chilled $0.1 \%$ ( $1 \mathrm{~g} /$ liter) peptone in an ice-water bath. Subsequent dilutions were made with unchilled peptone. Samples withdrawn during heating were immediately placed into $9 \mathrm{ml}$ of chilled $0.1 \%$ sterile peptone in an ice-water bath. Samples that did not need to be diluted were placed into chilled empty 50-ml test tubes in an ice-water bath. Subsequent dilutions were made with unchilled peptone. All samples were pour plated with TSAYE containing $0.1 \%(1 \mathrm{~g} / \mathrm{liter})$ pyruvate (Sigma Chemical Co., St. Louis, Mo.) and incubated at $37^{\circ} \mathrm{C}$ for $4 \mathrm{~h}$. Plates were then overlaid with modified Oxford agar (Becton Dickinson) and incubated at $37^{\circ} \mathrm{C}$ for an additional $68 \mathrm{~h}$. Colony counts were recorded as CFU per milliliter but were converted to log surviving fraction (LSF) before further analysis with the modified Gompertz equation.

Experimental design. The experiment was a complete $3 \times$ $3 \times 3$ factorial design of temperature $\left(55,60\right.$, or $\left.65^{\circ} \mathrm{C}\right)$, sodium lactate $(0,2.4$, or $4.8 \%)$, and sodium diacetate $(0,0.125$, or $0.25 \%$ ). Each treatment was conducted in triplicate, for a total of 81 experiments. At the same temperature, three treatments were heated simultaneously in the circulating water bath in three different round-bottom flasks. Treatment order and placement of the flasks in the bath were randomly selected to minimize variation between sets and to prevent variation due to heat distribution in the water bath.

Modeling. The data used to generate microbial survivor curves (LSF versus time) were analyzed with a modified version of the Gompertz equation (9):

$$
\mathrm{LSF}=C e^{-\mathrm{e}(A+B t)}-C e^{-\mathrm{e}(A)}
$$

where the parameters $A, B$, and $C$ describe three regions of the survivor curve. LSF was calculated by subtracting the baseline (time 0) counts from the counts for withdrawn samples. Parameter $A$ defines the shoulder of the curve, $B$ represents the maximum death rate, and $C$ is the overall change in survivors (initial minus final survivors) that is related to the start of the tailing region of the curve. To study the effects of temperature, sodium lactate, and sodium diacetate on each region of the curve in the full model analysis, the $A, B$, and $C$ parameters were calculated as a polynomial function of the single and interactive effects of the factors:

$$
\begin{aligned}
A= & a_{0}+a_{1} X_{1}+a_{2} X_{2}+a_{3} X_{3}+a_{13} X_{1} X_{3}+a_{12} X_{1} X_{2} \\
& +a_{23} X_{2} X_{3}+a_{123} X_{1} X_{2} X_{3} \\
B= & b_{0}+b_{1} X_{1}+b_{2} X_{2}+b_{3} X_{3}+b_{13} X_{1} X_{3}+b_{12} X_{1} X_{2} \\
& +b_{23} X_{2} X_{3}+b_{123} X_{1} X_{2} X_{3} \\
C= & c_{0}+c_{1} X_{1}+c_{2} X_{2}+c_{3} X_{3}+c_{13} X_{1} X_{3}+c_{12} X_{1} X_{2} \\
& +c_{23} X_{2} X_{3}+c_{123} X_{1} X_{2} X_{3}
\end{aligned}
$$


where $X_{1}$ is temperature $\left({ }^{\circ} \mathrm{C}\right), X_{2}$ is sodium diacetate concentration $(\%)$, and $X_{3}$ is sodium lactate concentration (\%). The estimates for these parameters were computed using least squares and nonlinear regression techniques (JMP, SAS Institute, Cary, N.C.). Temperature, sodium lactate concentration, and sodium diacetate concentration were converted into scaled variables $(-1,0$, or 1$)$ for development of the full model. Converting these variables into similar values allowed comparison between variables on the same scale. These variables were scaled, based on even distribution of the actual values tested, as follows: $X_{1}=\left(\right.$ temperature $\left.-60^{\circ} \mathrm{C}\right) /$ $5 ; X_{2}=(\%$ sodium diacetate $-0.125 \%) / 0.125 ; X_{3}=(\%$ sodium lactate $-2.4 \%) / 2.4$.

Before developing a full model that incorporated all data from the 81 experiments, a by-cell analysis for each of the 27 different treatment conditions was conducted to determine whether the modified Gompertz equation fit the data. Initially, the bycell analysis was done by fitting the Gompertz equation to survivor curves for each individual treatment set and all three replicates. During this analysis, parameter estimates were generated that provided the best fit to the Gompertz equation. If the data were capable of fitting the model and parameter estimates could be produced, the data converged.

Once the data converged in the by-cell analysis, a nonlinear regression model was used to fit the modified Gompertz equation using all treatment conditions. This was referred to as the full model analysis. Scaled variables, as calculated above, and parameter estimates from the full model were used to determine single and interactive effects. The full model calculated by the modified Gompertz equation used all the factors in the polynomial equations to estimate the $A, B$, and $C$ parameters.

Model validation. To validate the effectiveness of the full model for estimating LSF, additional experiments were done that were within the experimental range selected to develop the model but with treatment conditions not previously tested. Treatments used for validation were temperature $\left(57.5\right.$ and $\left.62.5^{\circ} \mathrm{C}\right)$, sodium lactate (1.2 and $3.6 \%$, equivalent to 12 and $36 \mathrm{~g} / \mathrm{liter}$, respectively), and sodium diacetate $(0.0625$ and $0.1875 \%$, equivalent to 0.625 and $1.875 \mathrm{~g} / \mathrm{liter}$, respectively). Because different concentrations of acidulants were used in these studies, additional frankfurter slurries were created with these concentrations. Plate counts were converted to LSFs to compare the experimental values of the validation studies with the predicted values obtained with the modified Gompertz equation.

Statistical analysis using thermal inactivation rates. Significant differences $(P<0.05)$ in linear inactivation rates $(D$ values) between all treatments were calculated and compared. $D$ values were determined for each replicate by plotting LSF against time, calculating the best-fit line, and calculating the negative inverse of the slope of the line. Tukey's test of means was used to compare factor level means, within heating temperature, with Statistical Analysis Software (SAS Institute).

\section{RESULTS AND DISCUSSION}

By-cell analysis for individual treatments. The data for most treatments converged with the modified Gompertz equation using the by-cell analysis. This resulted in stable parameter estimates and survivor curves that fit the experimental values well (observed visually). The parameter estimates of these treatments were evaluated for their ability to describe the shape of the microbial survival curves. Twenty-seven curves and parameter estimates were produced from the by-cell analysis; two of these curves (Fig.

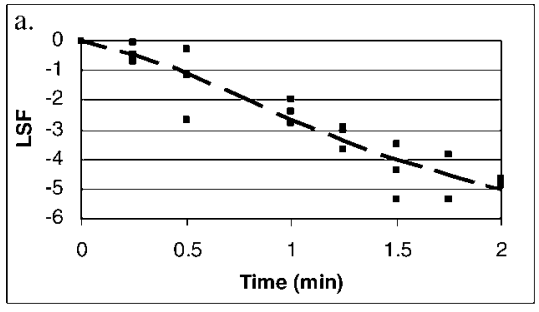

\begin{tabular}{l} 
By-cell Parameter \\
\hline Estimates: \\
\hline$A=0.98572$ \\
$B=-1.12172$ \\
$C=-6.91853$
\end{tabular}

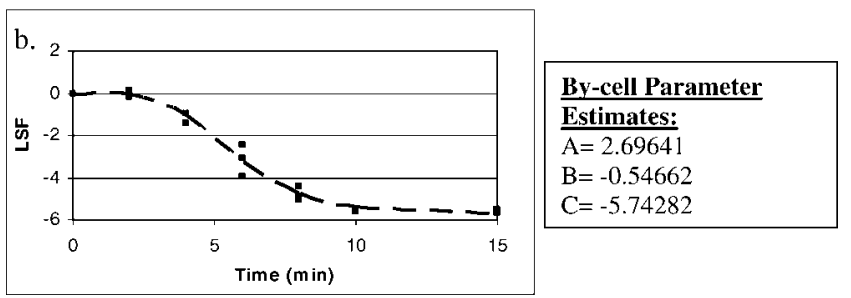

FIGURE 1. Examples of survivor curves and parameter estimates for treatments that converged with the modified Gompertz equation using the by-cell analysis. Treatments: (a) $65^{\circ} \mathrm{C}, 4.8 \%$ sodium lactate, $0 \%$ sodium diacetate; (b) $60{ }^{\circ} \mathrm{C}, 0 \%$ sodium lactate, $0 \%$ sodium diacetate. Observed data ( $\mathbf{\square})$; best-fit line with the modified Gompertz equation (---).

1) were selected to illustrate how curve shape was evaluated against parameter estimates.

For example, the $A$ value describes the shouldering region of survivor curves, with larger values corresponding to more prominent shoulders. Figure 1a was nearly linear and did not have a prominent shoulder; therefore, the $A$ parameter estimate was small (0.98752). Figure $1 \mathrm{~b}$ had a very prominent shoulder; hence, the $A$ parameter value was large (2.69641) in comparison. The $B$ parameter denotes the most rapid death rate; therefore, a more negative $B$ value indicates a faster death rate. Because the population is decreasing, this value is always negative and a steeper slope implies a faster rate of cell death. Figure 1a had the steeper slope, and the $B$ parameter $(-1.12172)$ was more negative than that shown in Figure $1 \mathrm{~b}(-0.54662)$, indicating that cells died faster at $65^{\circ} \mathrm{C}$ than at $60^{\circ} \mathrm{C}$. Similar relationships were observed between the shape of the inactivation curves and the $C$ parameter estimates, which are associated with the tailing portion of the curves. In general, the $C$ parameter estimates the LSF value where the tail begins. For example, Figure 1b had a $C$ parameter value of -5.74282 meaning that the tail began at an LSF value of around -5 to -6 $\log$. The $C$ parameter value can also be evaluated such that a less negative (closer to zero) $C$ value corresponds to a tail that begins at a lower log reduction. When comparing $C$ parameter estimates between treatments, it is also necessary to look at the total log reduction achieved because this can alter the interpretation of the $C$ value. For example, Figure 1a did not exhibit a prominent tail within the time range of the curve. As observed on the $y$ axis, the total reduction in cell population was approximately $5 \mathrm{log}$ and the $C$ value was -6.91853 . Because the $C$ parameter approximates when the tail begins and in this case assumed a total log reduction (6.91853) greater than the actual total reduction in cell population $(\sim 5 \log )$, a tail region was not expected.

Twenty-three of the 27 treatment sets converged with 


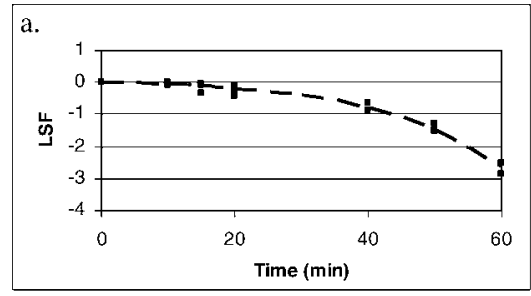

\begin{tabular}{|l|}
\hline By-cell Parameter \\
\hline Estimates: \\
$A=2.47287$ \\
$B=-0.00690$ \\
$C=-6720.78$ \\
\hline
\end{tabular}

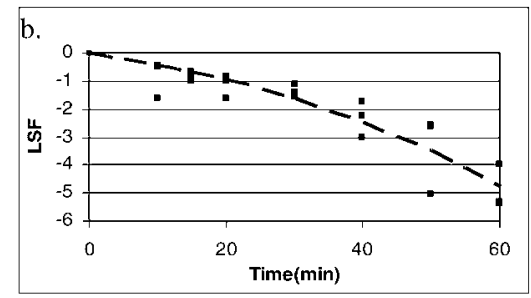

\begin{tabular}{|l|}
\hline By-cell Parameter \\
\hline Estimates: \\
\hline$A=1.88738$ \\
$B=-0.00457$ \\
$C=-904.873$ \\
\hline
\end{tabular}

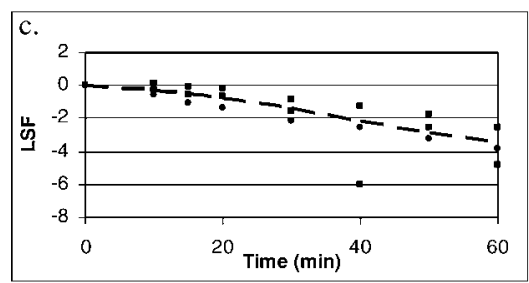

\section{Bv-cell Parameter}

Estimates:

$\mathrm{A}=1.36592$

$\mathrm{B}=-0.03817$

$\mathrm{C}=-5.23$

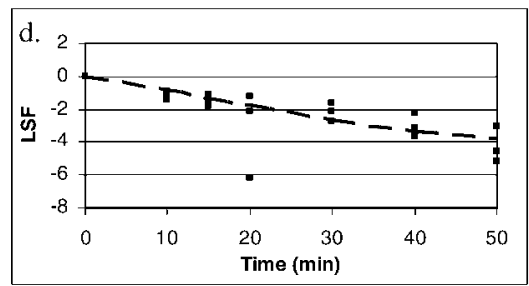

\begin{tabular}{|l|}
\hline By-cell Parameter \\
\hline Estimates: \\
$\mathrm{A}=0.78968$ \\
$\mathrm{~B}=-0.05158$ \\
$\mathrm{C}=-5.14225$ \\
\hline
\end{tabular}

FIGURE 2. Examples of survivor curves for treatments that did not converge with the modified Gompertz equation using the bycell analysis. Treatments (all at $55^{\circ} \mathrm{C}$ ): (a) $2.4 \%$ sodium lactate, $0 \%$ sodium diacetate; (b) $2.4 \%$ sodium lactate, $0.125 \%$ sodium diacetate; (c) $4.8 \%$ sodium lactate, $0.125 \%$ sodium diacetate; $(d)$ $4.8 \%$ sodium lactate, $0.25 \%$ sodium diacetate. Observed data

$\square)$; best-fit line with the modified Gompertz equation (---).

our statistical approach and the Gompertz equation. Survivor curves from the by-cell analysis modeled the experimental data well, and the parameter estimates predicted curve shape in the converged treatment sets, but analysis of treatment sets that did not converge was needed before developing the full model using the modified Gompertz equation. Examples of survivor curves for the treatments that did not converge are shown in Figure 2. Inability of data to converge could be due to numerous factors, including variability in the raw data and the complexity of the modified Gompertz equation. The data sets that did not converge were all from the $55^{\circ} \mathrm{C}$ treatments: (i) $2.4 \%$ sodium lactate and $0 \%$ sodium diacetate, (ii) $2.4 \%$ sodium lactate and $0.125 \%$ sodium diacetate, (iii) $4.8 \%$ sodium lactate and $0.125 \%$ sodium diacetate, and (iv) $4.8 \%$ sodium lactate and $0.25 \%$ sodium diacetate.

At $55^{\circ} \mathrm{C}$, there were examples where the data did not converge and the fit to the Gompertz model could not provide stable parameter estimates (Fig. 2a through 2d). In most cases, lack of convergence was for data sets that led to a 4-log reduction or less (Fig. 2a, 2c, and 2 d). In only one case, for cells heated in $2.4 \%$ sodium lactate and
$0.125 \%$ sodium diacetate (Fig. $2 b$ ), convergence was not found for a greater than 4-log reduction. A longer thermal treatment time might allow for convergence at $55^{\circ} \mathrm{C}$. The modified Gompertz equation can model several curve shapes; however, it is unknown why the data from the concave curve shown in Figure $2 \mathrm{~b}$ was unable to converge because the total reduction of this treatment was greater than $4 \log$. Although the data did not converge statistically with the modified Gompertz equation under these treatment conditions, the line generated by the Gompertz equation was still similar (seen visually) to that for the data points obtained in the experiment.

Lack of convergence in a by-cell analysis does not mean that the data cannot be used in a full model. Graphical depictions of the treatments that did not converge generated a best-fit line that was similar to that for the experimental data, suggesting that these treatments could be used. Evaluation of the by-cell analysis indicated that the modified Gompertz equation did model the experimental data well, so a full model was developed with the complete data set.

Full model analysis. A full model for all 27 treatment conditions was developed with the modified Gompertz equation and nonlinear regression techniques. The $R^{2}$ value for the full model was 0.9437 . This relatively high value implies that the parameters were good predictors of the shape of the inactivation curve and the LSF values. Comparison of survivor curves between the by-cell analysis and full model analysis revealed similar results at all temperatures, except that the shouldering and tailing regions were more pronounced at $55^{\circ} \mathrm{C}$ than those for the observed data and the by-cell analysis (Fig. 3). The full model produced 27 curves, each with its own parameter estimates. Two of these curves are shown in Figure 3.

All three factors (temperature, sodium lactate, and sodium diacetate) affected curve shape, but temperature had the most definitive effect. At higher treatment temperatures such as $65^{\circ} \mathrm{C}$, the curves became more linear (Fig. 3b), whereas very prominent shoulders and tailing regions were seen at $55^{\circ} \mathrm{C}$ (Fig. 3a). The full model predicted LSF better at 60 and $65^{\circ} \mathrm{C}$ when the curves became more linear. All the full model curves at $55^{\circ} \mathrm{C}$ were sigmoidal, but the experimental data usually were more linear or had a slight shoulder (data not shown), which usually resulted in an overestimation of survival at the beginning and end of the heat treatment and an underestimation of survival in the middle of the treatment (Fig. 3a). Although the parameter estimates were not obtained by convergence of the data at $55^{\circ} \mathrm{C}$, they are still useful for predicting the overall shape of the survivor curve and in some cases can still provide good approximations of LSF.

Because some treatments did not converge in the bycell analysis, evaluation of these treatments in the full model was needed to support the full model under all experimental conditions. Figure 4 contains the by-cell and full model curves for one of the treatments that did not converge in the by-cell analysis. For the treatments whose data did not converge, the full model does not predict LSF as well as it does for converged data treatments. As expected, 

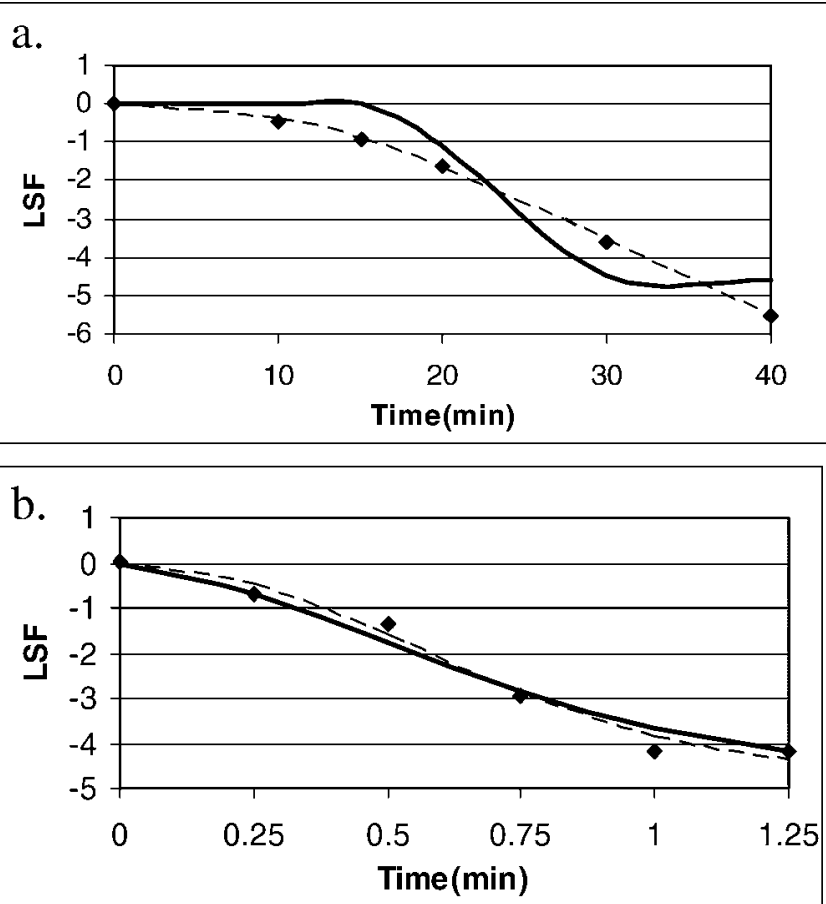

FIGURE 3. Examples of survivor curves from the by-cell and full model developed by the modified Gompertz equation. Treatments depicted did converge in the by-cell analysis: (a) $55^{\circ} \mathrm{C}, 0 \%$ sodium lactate, $0.25 \%$ sodium diacetate; (b) $65^{\circ} \mathrm{C}, 0 \%$ sodium lactate, $0.25 \%$ sodium diacetate. Observed data ( $\mathbf{\square}) ;$ by-cell fitted data (---); full model fitted data (-).

in these situations, the full model predicted a sigmoidal curve when the experimental data tended to follow a more linear pattern. The by-cell analysis usually predicted data better because the parameters were developed for a specific treatment, whereas the full model parameters were developed with data from all 27 treatments. Greater variability was expected in the full model; therefore, many factors were taken into consideration. Although differences did occur between observed, by-cell, and full model values, the parameter estimates did fit the experimental data well under most conditions, thereby justifying the use of the full model for predicting LSF within the various experimental ranges used in this study.

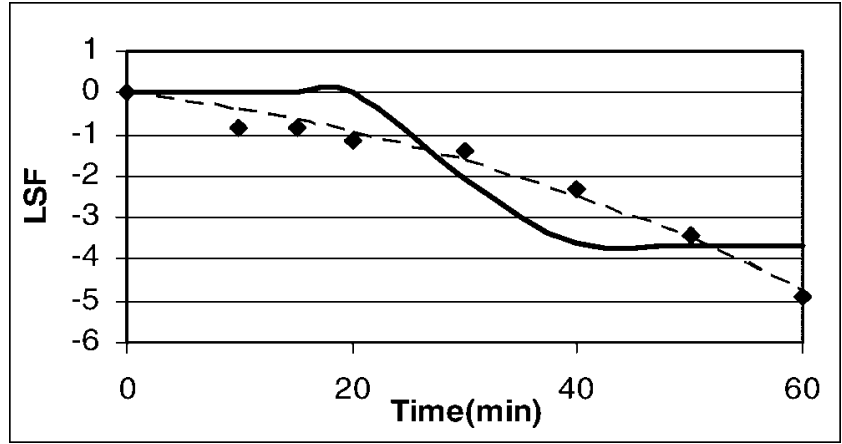

FIGURE 4. Survivor curve from the by-cell and full model analyses developed by the modified Gompertz equation. Treatment: $55^{\circ} \mathrm{C}, 2.4 \%$ sodium lactate, $0.125 \%$ sodium diacetate. Observed

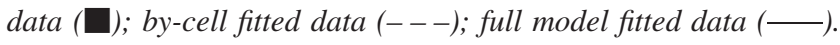

TABLE 1. Parameter estimates for the A coefficient in the full model developed by the modified Gompertz equation

\begin{tabular}{lcc}
\hline & \multicolumn{2}{c}{$A$ coefficient } \\
\cline { 2 - 3 } Parameter $^{a}$ & $\begin{array}{c}\text { Parameter } \\
\text { estimate }\end{array}$ & $\begin{array}{c}\text { Approximate } \\
\text { standard error }\end{array}$ \\
\hline$a_{0}{ }^{b}$ & 5.2095 & 0.5937 \\
$a_{1}{ }^{b}$ & -4.1556 & 0.4606 \\
$a_{2}$ & -0.1955 & 0.4548 \\
$a_{3}$ & -0.1291 & 0.6502 \\
$a_{12}$ & 0.1713 & 0.3621 \\
$a_{13}$ & 0.1204 & 0.5126 \\
$a_{23}$ & -0.2605 & 0.5322 \\
$a_{123}$ & 0.1250 & 0.4294 \\
\hline
\end{tabular}

${ }^{a} a_{0}$, intercept; $a_{1}$, temperature effect; $a_{2}$, sodium diacetate effect; $a_{3}$, sodium lactate effect.

${ }^{b}$ Effect significant at $P<0.05$.

Analysis of single and multiple factor interactions. Temperature, sodium lactate concentration, and sodium diacetate concentration were incorporated into the full model by making the $A, B$, and $C$ parameters of the modified Gompertz equation a polynomial function of the factors (Tables 1 through 3 ). Relatively few parameters significantly affected the $A, B$, and $C$ estimates $(P<0.05$ or $P$ $<0.10$ ). This finding is not surprising because all single factors and two-way and three-way interactions were incorporated into the models, causing the polynomial equations to become very complex.

The effects of single factors on the three regions of the survivor curve can be determined by the LSF values in Tables 1 through 3 . Values for temperature $\left(a_{1}\right)$, sodium diacetate concentration $\left(a_{2}\right)$, and sodium lactate concentration $\left(a_{3}\right)$ were negative and had an inverse relationship with the $A$ parameter; thus, as the LSF values for temperature, sodium diacetate, or sodium lactate increased individually, $A$ decreased and the shouldering region became less prominent (Table 1). The same comparisons could be made with the $B$ and $C$ parameters. As LSF values for temperature

TABLE 2. Parameter estimates for the B coefficient in the full model developed by the modified Gompertz equation

\begin{tabular}{lrc}
\hline & \multicolumn{2}{c}{$B$ coefficient } \\
\cline { 2 - 3 } Parameter $^{a}$ & $\begin{array}{c}\text { Parameter } \\
\text { estimate }\end{array}$ & $\begin{array}{c}\text { Approximate } \\
\text { standard error }\end{array}$ \\
\hline$b_{0}{ }^{b}$ & -1.1254 & 0.1311 \\
$b_{1}{ }^{b}$ & -0.7953 & 0.0977 \\
$b_{2}{ }^{c}$ & -0.1878 & 0.1039 \\
$b_{3}$ & 0.1226 & 0.1447 \\
$b_{12}$ & -0.0663 & 0.0817 \\
$b_{13}$ & 0.0958 & 0.1080 \\
$b_{23}$ & 0.0284 & 0.1215 \\
$b_{123}$ & 0.0428 & 0.0955 \\
\hline
\end{tabular}

${ }^{a} b_{0}$, intercept; $b_{1}$, temperature effect; $b_{2}$, sodium diacetate effect; $b_{3}$, sodium lactate effect.

${ }^{b}$ Effect significant at $P<0.05$.

${ }^{c}$ Effect significant at $P<0.10$. 
TABLE 3. Parameter estimates for the $\mathrm{C}$ coefficient in the full model developed by the modified Gompertz equation

\begin{tabular}{lcc}
\hline & \multicolumn{2}{c}{$C$ coefficient } \\
\cline { 2 - 3 } Parameter $^{a}$ & $\begin{array}{c}\text { Parameter } \\
\text { estimate }\end{array}$ & $\begin{array}{c}\text { Approximate } \\
\text { standard error }\end{array}$ \\
\hline$c_{0}{ }^{b}$ & -4.8790 & 0.1849 \\
$c_{1}{ }^{b}$ & -1.1830 & 0.2221 \\
$c_{2}$ & 0.0013 & 0.1899 \\
$c_{3}$ & 0.3275 & 0.2188 \\
$c_{12}$ & 0.0587 & 0.2329 \\
$c_{13}$ & -0.3678 & 0.2600 \\
$c_{23}$ & -0.3793 & 0.2210 \\
$c_{123}$ & -0.5043 & 0.2702 \\
\hline
\end{tabular}

${ }^{a} c_{0}$, intercept; $c_{1}$, temperature effect; $c_{2}$, sodium diacetate effect; $c_{3}$, sodium lactate effect.

${ }^{b}$ Effect significant at $P<0.05$.

$\left(b_{1}\right)$ or sodium diacetate concentration $\left(b_{2}\right)$ increased, the $B$ parameter decreased and the death rate increased (Table 2). An increase in the LSF value for sodium lactate concentration $\left(b_{3}\right)$ caused an increase in $B$, and the death rate decreased. The temperature LSF value $\left(c_{1}\right)$ was negative in relation to the $C$ parameter, so an increase caused a decrease in $C$ and the tail began at a more negative value (Table 3 ). Sodium diacetate $\left(c_{2}\right)$ and sodium lactate $\left(c_{3}\right)$ LSF values were positive in relation to $C$, so an increase caused the tail to begin at a less negative value (Table 3). A longer shoulder and lower death rate and the presence of tails is related to increased heat resistance in those regions of the survivor curve; therefore, heat resistance in each region had a variable relationship to the experimental factors. If only single factors were reviewed, LM cells were more thermotolerant at the beginning of the heat treatment at lower temperatures and lower concentrations of sodium diacetate and sodium lactate. As the heat treatment continued, cells became more thermotolerant at lower temperatures and lower sodium diacetate concentrations. At the end of the treatment, the cells that persisted were more heat resistant at lower temperatures and at higher concentrations of acidulants. These trends did not always hold, however, because interactions between treatment factors sometimes resulted in synergism or antagonism, which altered heat resistance.

Because the $B$ parameter is related to the maximum death rate, it can be indirectly compared to thermal inactivation rates ( $D$-values). In the current study, sodium lactate also caused an increase in LM heat resistance in the maximum death region of the survivor curve. In other studies, contradicting results with no significant changes in heat resistance or with microorganisms being less resistant in the presence of lactates have been found. In minced beef, LM heat resistance at $55^{\circ} \mathrm{C}$ was significantly less $(P<0.001)$ with increasing concentrations of sodium lactate (0 to $4.8 \%$ ) (12). There has not been much research on the effects of sodium diacetate, alone or in combination with lactates, on the thermal inactivation of LM. Juneja (8) suggested that addition of sodium diacetate (0 to $0.25 \%$ ) alone resulted in an increase in heat resistance of LM. However, when the sodium lactate ( 0 to $4.8 \%$ ) and sodium diacetate ( 0 to $0.25 \%$ ) were combined in ground beef, heat resistance decreased. This result contrasts with those from the current study, in which an increase in sodium diacetate $\left(b_{2}\right)$ caused an increase in the death rate (less heat resistant), but the simultaneous increase in both acidulants $\left(b_{23}\right)$ caused the death rate to decrease (more heat resistant) (Table 2).

Contrasting results for the effects of sodium lactate, sodium diacetate, and heat on LM thermotolerance could be a result of interactions between the factors, where at certain concentrations and/or temperatures, synergism occurs but antagonism occurs under other treatment conditions. The advantage of using the modified Gompertz equation for predictive modeling is that interactive effects can be compared to determine whether some trends are different for different levels of the other factors. For example, if temperature is held constant at $X_{1}=X_{10}$ and the equation for parameter $B$ is rewritten to isolate $X_{10}$, the effects of sodium diacetate, sodium lactate, and their interaction on the maximum death rate ( $B$ parameter) could be studied. The equation for the $B$ parameter would then be $B=b_{\mathrm{o}}+$ $b_{1} X_{10}+\left(b_{2}+b_{12} X_{10}\right) X_{2}+\left(b_{3}+b_{13} X_{10}\right) X_{3}+\left(b_{23}+\right.$ $\left.b_{123} X_{10}\right) X_{2} X_{3}$.

The values for the coefficients (Table 2) could then be inserted into this equation to become $B=-1.1254+$ $-0.7953 X_{10}+\left(-0.1878-0.0663 X_{10}\right) X_{2}+(0.1226+$ $\left.0.0958 X_{10}\right) X_{3}+\left(0.0284+0.0428 X_{10}\right) X_{2} X_{3}$. The effects of sodium diacetate, sodium lactate, and their interaction are evaluated by the value of their coefficients: $-0.1878-$ $0.0663 X_{10}, 0.1226+0.0958 X_{10}$, and $0.0284+0.0428 X_{10}$, respectively. The scaled values of $X_{10}$ in this experiment were $-1\left(55^{\circ} \mathrm{C}\right), 0\left(60^{\circ} \mathrm{C}\right)$, and $1\left(65^{\circ} \mathrm{C}\right)$, which can be inserted into these coefficients to determine whether the effects of certain factors stay consistent or change with a change in temperature. Equations for the $A, B$, and $C$ parameters can be written to isolate $X_{2}$ or $X_{3}$ to study other interactions.

Notable effects of interactions on the $B$ parameter were observed when these calculations were done. When $B$ was written to isolate $X_{1}$, the coefficient for $X_{2}$ remained negative and $X_{3}$ remained positive at all temperatures. The interaction between $X_{2}$ and $X_{3}\left(X_{2} X_{3}\right)$, however, was not consistent across all temperatures. When $X_{10}=-1$, the $X_{2} X_{3}$ coefficient was negative, but when $X_{10}=0$ or 1 , the value of the interaction coefficient was positive. By setting the coefficient $\left(0.0284+0.0428 X_{10}\right)$ equal to zero, a $X_{10}$ value of -0.664 resulted in a coefficient equal to zero; thus, $X_{10}$ $<-0.664$ resulted in a negative coefficient and $X_{10}>$ -0.664 gave a positive coefficient. Because the equation is $X_{1}=$ (temperature -60$) / 5$ ); a value of -0.664 equates to $56.7^{\circ} \mathrm{C}$. At temperatures above $56.7^{\circ} \mathrm{C}$, an increase in both sodium lactate and sodium diacetate caused a decrease in the death rate, i.e., LM cells became more thermotolerant. At temperatures below $56.7^{\circ} \mathrm{C}$, an increase in both sodium lactate and sodium diacetate caused an increase in the death rate, i.e., cells became less thermotolerant. The other $B$ parameter interactive coefficients did not change as factors were varied; rather, the trends stayed consistent at all factor levels. For all sodium diacetate concentrations, the temper- 
ature $\times$ sodium lactate interaction $\left(b_{13}\right)$ was positive; therefore, increases in both caused a decrease in the death rate. At all concentrations of sodium lactate, the temperature $X$ sodium diacetate interaction $\left(b_{12}\right)$ was negative; therefore, an increase in both resulted in an increase in the death rate.

Although several $A$ (shouldering) and $C$ (tailing) parameter interactions varied with factor level, only the $B$ (maximum death rate) parameter is described here in detail because this parameter was the most important value for making comparisons of microbial heat resistance. Based on single and interactive factors, some general conclusions can be made about which factor levels affect heat resistance. At all temperatures and sodium lactate concentrations, an increase in sodium diacetate caused cells to be less heat resistant. At all temperatures and sodium diacetate concentrations, increases in sodium lactate made cells more resistant. At all sodium lactate concentrations, increases in both temperature and sodium diacetate made cells less resistant. At all sodium diacetate concentrations, increases in temperature and sodium lactate caused cells to be more resistant. Cells also became less resistant at temperatures less than $56.7^{\circ} \mathrm{C}$ when sodium lactate and sodium diacetate were used in combination; however, this interaction was not synergistic and sodium diacetate alone resulted in less resistant cells. If only the $B$ parameter is examined, these results would suggest that temperature and sodium diacetate decreased resistance and sodium lactate increased heat resistance.

Model validation analysis. Model validation experiments were done to test the effectiveness of the full model at predicting LSF under conditions not used to develop the model but within the experimental range $\left(55\right.$ to $65^{\circ} \mathrm{C}, 0$ to $4.8 \%$ sodium lactate, and 0 to $0.25 \%$ sodium diacetate). The conditions tested were temperature $\left(57.5\right.$ and $\left.62.5^{\circ} \mathrm{C}\right)$, sodium diacetate $(0.0625$ and $0.1875 \%)$, and sodium lactate (1.2 and 3.6\%). Survivor curves for some of the validation treatments are shown in Figure 5. Curves were sigmoidal at $57.5^{\circ} \mathrm{C}$ (Fig. 5a) and were near linear or had large shouldering regions at $62.5^{\circ} \mathrm{C}$ (Fig. 5b). At $62.5^{\circ} \mathrm{C}$, the full model underestimated the thermal treatment and had predicted values that were usually higher than the experimental values. In sigmoidal curves at $57.5^{\circ} \mathrm{C}$, the full model did the best job of predicting LSF at the beginning of the thermal treatment but inaccurately modeled LSF in the remainder of the curve, and differences between predicted and observed values at some points were more than $2 \log$ units. These differences are a concern because if processors use the full model to determine a postprocessing pasteurization treatment for frankfurters, the model could inaccurately estimate the treatment needed. This problem is of special importance at $57.5^{\circ} \mathrm{C}$ because the curves overestimated thermal death. Because the model underestimated death at $62.5^{\circ} \mathrm{C}$, there is an extra margin of safety when the full model is used to determine a thermal treatment at this temperature. For example, the full model predicted a $2-\log$ reduction at $2 \mathrm{~min}$ (Fig. 5b) when there was actually an approximately 5-log reduction. Although this estimate gives an added margin of
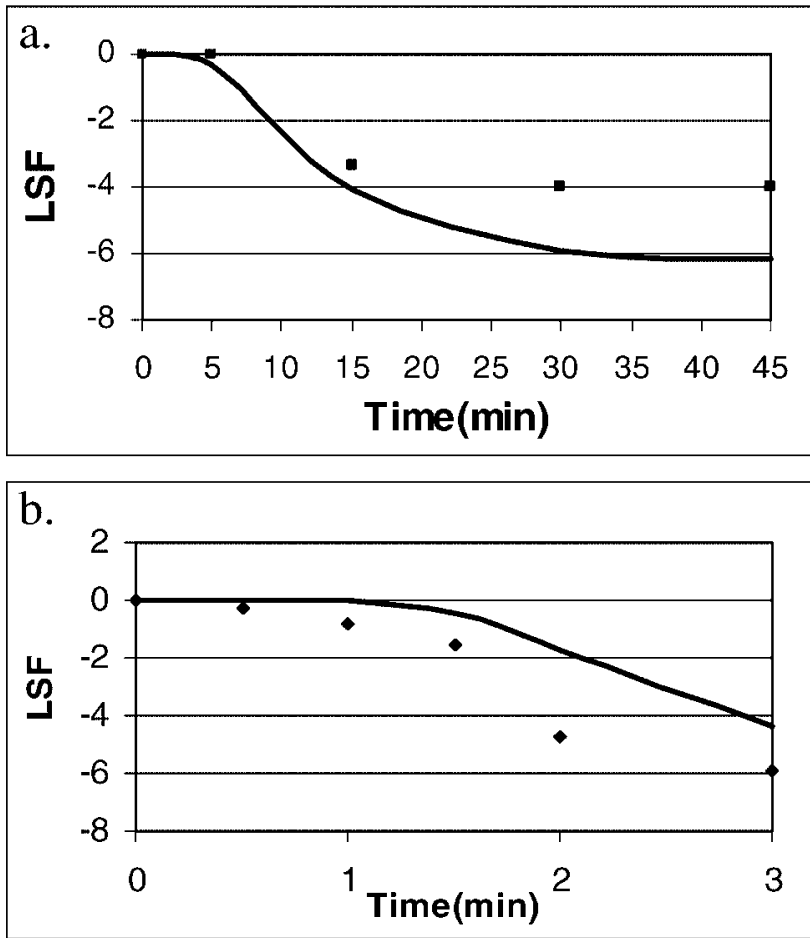

FIGURE 5. Survivor curves from the full model analysis of validation treatments developed by the modified Gompertz equation. Treatments in single replicate: (a) $57.5^{\circ} \mathrm{C}, 3.6 \%$ sodium lactate, $0.0625 \%$ sodium diacetate; (b) $62.5^{\circ} \mathrm{C}, 1.2 \%$ sodium lactate, $0.0625 \%$ sodium diacetate. Observed data ( $\mathbf{\square}) ;$ full model fitted data (—).

safety, it could cause overprocessing of the product, which could affect product quality.

Although the data were underestimated, the data were modeled better at $62.5^{\circ} \mathrm{C}$ than at $57.5^{\circ} \mathrm{C}$. This finding was similar to that for the experimental data used to develop the model, when the model was more accurate at higher temperatures. In addition, validation experiments were done in a single trial, so more reliable results might have been obtained by doing additional replicates. Postprocessing pasteurization will likely be done at higher temperatures, which is preferable because the model was more reliable at temperatures above $62.5^{\circ} \mathrm{C}$.

Comparison of thermal inactivation rates. The modified Gompertz equation provided information about single and interactive effects between factors. Temperature, sodium lactate, and sodium diacetate had significant effects on inactivation rates $(P<0.001)$. As temperature or sodium diacetate concentration increased, $D$-values decreased. As sodium lactate concentration increased, $D$-values increased. Increased LM heat resistance by addition of sodium lactate has been observed by other researchers in ground beef (8) and chicken meat (14). In poultry meat, $D$-values at $55^{\circ} \mathrm{C}$ significantly increased $(P<0.05)$ from 38.9 to $82.8 \mathrm{~min}$ when sodium lactate $(4.8 \%)$ was added (14). This trend has been inconsistent, however; McMahon et al. (12) reported decreased heat resistance for LM in ground beef, and Porto et al. (15) reported no difference when using potassium lactate in reheated frankfurters. Little research has been 
TABLE 4. D-values of Listeria monocytogenes in frankfurter slurry as affected by temperature and sodium lactate and sodium diacetate concentrations

\begin{tabular}{|c|c|c|c|c|}
\hline \multirow[b]{2}{*}{$\begin{array}{l}\text { Tempera- } \\
\text { ture }\left({ }^{\circ} \mathrm{C}\right)\end{array}$} & \multirow{2}{*}{$\begin{array}{c}\text { Sodium } \\
\text { lactate } \\
(\%)\end{array}$} & \multirow{2}{*}{$\begin{array}{c}\text { Sodium } \\
\text { diacetate } \\
(\%)\end{array}$} & \multicolumn{2}{|c|}{$D$-value } \\
\hline & & & Mean $^{a}$ & $\begin{array}{l}\text { Standard } \\
\text { deviation }\end{array}$ \\
\hline \multirow[t]{9}{*}{55} & 0 & 0 & $14.0 \mathrm{BC}$ & 1.210 \\
\hline & 0 & 0.125 & $8.1 \mathrm{DE}$ & 0.666 \\
\hline & 0 & 0.25 & $7.4 \mathrm{E}$ & 0.985 \\
\hline & 2.4 & 0 & $24.4 \mathrm{~A}$ & 1.801 \\
\hline & 2.4 & 0.125 & $13.6 \mathrm{BC}$ & 2.359 \\
\hline & 2.4 & 0.25 & $11.4 \mathrm{CD}$ & 2.974 \\
\hline & 4.8 & 0 & $25.1 \mathrm{~A}$ & 3.553 \\
\hline & 4.8 & 0.125 & $17.7 \mathrm{AB}$ & 6.542 \\
\hline & 4.8 & 0.25 & $13.8 \mathrm{BC}$ & 4.133 \\
\hline \multirow[t]{9}{*}{60} & 0 & 0 & $2.2 \mathrm{C}$ & 0.000 \\
\hline & 0 & 0.125 & $1.6 \mathrm{E}$ & 0.100 \\
\hline & 0 & 0.25 & $3.0 \mathrm{~A}$ & 1.270 \\
\hline & 2.4 & 0 & $2.9 \mathrm{~A}$ & 0.058 \\
\hline & 2.4 & 0.125 & $2.2 \mathrm{C}$ & 0.379 \\
\hline & 2.4 & 0.25 & $1.8 \mathrm{DE}$ & 0.529 \\
\hline & 4.8 & 0 & $2.6 \mathrm{~B}$ & 0.173 \\
\hline & 4.8 & 0.125 & $2.5 \mathrm{~B}$ & 0.361 \\
\hline & 4.8 & 0.25 & $1.7 \mathrm{D}$ & 0.379 \\
\hline \multirow[t]{9}{*}{65} & 0 & 0 & $0.2 \mathrm{C}$ & 0.017 \\
\hline & 0 & 0.125 & $0.2 \mathrm{C}$ & 0.061 \\
\hline & 0 & 0.25 & $0.2 \mathrm{C}$ & 0.051 \\
\hline & 2.4 & 0 & $0.3 \mathrm{C}$ & 0.006 \\
\hline & 2.4 & 0.125 & $0.3 \mathrm{C}$ & 0.090 \\
\hline & 2.4 & 0.25 & $0.3 \mathrm{C}$ & 0.032 \\
\hline & 4.8 & 0 & $0.4 \mathrm{BC}$ & 0.036 \\
\hline & 4.8 & 0.125 & $0.5 \mathrm{AB}$ & 0.197 \\
\hline & 4.8 & 0.25 & $0.2 \mathrm{C}$ & 0.017 \\
\hline
\end{tabular}

${ }^{a}$ Values are mean of three replicates. Between rows within the same heating temperature, means with different letters are significantly different $(P<0.05)$.

done using sodium diacetate in combination with lactate to study heat resistance. Juneja ( 8 ) found that sodium diacetate (0 to $0.25 \%$ ) increased heat resistance when added alone to ground beef but caused a decrease when added to formulations containing sodium lactate (0 to $4.8 \%)$.

The effects of sodium lactate and sodium diacetate have been postulated to be $\mathrm{pH}$ related $(8,12)$. Many studies on heat inactivation were done in ground beef or poultry meats rather than cured meat products. The $\mathrm{pH}$ differences between these products and the frankfurter slurries used in the current study could have contributed to these differences. $\mathrm{pH}$ could also be responsible for the inverse effects of sodium lactate and sodium diacetate on thermal inactivation in the current study. The addition of sodium lactate significantly increased the $\mathrm{pH}$ of the frankfurter slurry $(P<$ 0.001 ), whereas the addition of sodium diacetate resulted in a decrease in $\mathrm{pH}(P<0.001)$. The average $\mathrm{pH}$ for the unamended frankfurter slurry was 5.92. Addition of the highest concentration of sodium diacetate $(0.25 \%)$ lowered the $\mathrm{pH}$ to 5.35 , and the addition of the highest concentration of sodium lactate increased $\mathrm{pH}$ to 6.23 . The combination of high temperature and reduced $\mathrm{pH}$ could have been too many hurdles for LM cells to overcome, so the addition of diacetate resulted in faster death. However, because lactate increased $\mathrm{pH}$, cells could have overcome the lethal effects of heat and persisted for longer periods.

There was also interest in testing for significant differences between treatments. Significant differences could have been determined by comparing confidence intervals of the parameter estimates between treatments; however, confidence intervals were unstable under several treatment conditions. Instability of confidence intervals is common because of the complexity of the function used to calculate the intervals when several factors are involved.

Therefore, to compare microbial heat resistance values between treatments, $D$-values were calculated for each replicate using a linear regression approach, and Tukey's means comparison was completed to compare linear inactivation rates at each of the heating temperatures (Table 4). At 55 and $60^{\circ} \mathrm{C}, D$-values obtained for $2.4 \%$ sodium lactate and $0 \%$ diacetate were among the highest $(P<0.05)$. At $65^{\circ} \mathrm{C}$, this trend was not observed.

Because temperature affected the action of sodium lactate and sodium diacetate, tests for significant differences between interactions were done (Table 5). The interaction between the acidulant salts was not significant $(P=$ $0.1633)$. The interactions between sodium lactate and temperature and sodium diacetate and temperature, however, were significant $(P<0.001)$.

The modified Gompertz equation was a useful tool for modeling thermal inactivation of LM. This equation produced a more accurate model of the data at higher temperatures but provided good estimates of LSF over all treat-

TABLE 5. Statistical analysis of the effects of single factors and their interactions on thermal inactivation rates of LM in frankfurter slurry ${ }^{a}$

\begin{tabular}{|c|c|c|c|c|c|}
\hline Source & df & Type I SS & Mean square & $F$ value & $\operatorname{Pr}>F$ \\
\hline Temperature & 2 & $3,463.676336$ & $1,731.83817$ & 490.27 & $<0.0001$ \\
\hline Lactate & 2 & 135.930106 & 67.965053 & 19.24 & $<0.0001$ \\
\hline Diacetate & 2 & 190.893202 & 95.446601 & 27.02 & $<0.0001$ \\
\hline Temp $\times$ lactate & 4 & 260.090879 & 65.02272 & 18.41 & $<0.0001$ \\
\hline Temp $\times$ diacetate & 4 & 334.374405 & 83.593601 & 23.66 & $<0.0001$ \\
\hline Lactate $\times$ diacetate & 4 & 24.034012 & 6.008503 & 1.7 & 0.1633 \\
\hline Temp $\times$ lactate $\times$ diacetate & 8 & 21.454691 & 2.681836 & 0.76 & 0.6396 \\
\hline
\end{tabular}

${ }^{a} \mathrm{df}$, degrees of freedom; SS, sum of squares; Pr, probability. 
ment conditions. At the lower temperature studied, the model should be used to only approximate LSF because some parameter estimates were unstable at $55^{\circ} \mathrm{C}$. The interactive effects observed in this research may be important to frankfurter processors who utilize acidulants in their product formulations and who apply a postprocess intervention. To prevent LM cells from becoming more heat resistant due to the presence of sodium lactate, temperatures and acidulant concentrations must be studied in more detail. Interactions between the factors were complex, but higher temperatures, higher sodium diacetate concentrations, and lack of sodium lactate in general produced cells with the least heat resistance. Because many processors utilize sodium lactate to prevent LM growth during shelf life, formulations must be optimized also to prevent cells from becoming more resistant to postprocessing pasteurization temperatures.

According to the 2003 FDA-USDA-FSIS-CDC LM risk assessment, contamination of frankfurters at retail is usually less than $1 \log \mathrm{CFU} / \mathrm{g}$ (17). Although rare, contamination of 1 to $2 \log \mathrm{CFU} / \mathrm{g}$ has been identified in retail frankfurters (17). Based on this information, a 3- to 4-log reduction process would be a conservative lethal treatment for postprocessing pasteurization. Because lactates increase LM heat resistance, a 3- or 4-D process also should be sufficient to eliminate heat-resistant LM cells on frankfurters containing these acidulants.

\section{ACKNOWLEDGMENTS}

This research was funded by the National Alliance for Food Safety and Security through a USDA-Agricultural Research Service Cooperative Agreement. We thank Emily Becker and the undergraduate students in the Food Safety Laboratory at Purdue University for their work on this project. Further appreciation is extended to Dr. Hans Carter and Tiffani McCann for providing assistance with statistical analysis of the data.

\section{REFERENCES}

1. Baranyi, J., and M. L. Tamplin. 2004. ComBase: a common database on microbial responses to food environments. $\underline{\text { J. Food Prot. 67: }}$ 1967-1971.

2. Centers for Disease Control and Prevention. 1998. Multistate outbreak of listeriosis-United States, 1998. Morb. Mortal. Wkly. Rep. 49:1085-1086.

3. Chhabra, A. T., W. H. Carter, R. H. Linton, and M. A. Cousin. 1999. A predictive model to determine the effects of $\mathrm{pH}$, milkfat, and temperature on thermal inactivation of Listeria monocytogenes. J. Food Prot. 62:1143-1149.

4. Chhabra, A. T., W. H. Carter, R. H. Linton, and M. A. Cousin. 2002.
A predictive model that evaluates the effect of growth conditions on the thermal resistance of Listeria monocytogenes. Int. J. Food Microbiol. 78:235-243.

5. Fenlon, D. R. 1999. Listeria monocytogenes in the natural environment, p. 21-38. In E. T. Ryser and E. H. Marth (ed.), Listeria, listeriosis, and food safety, 2nd ed. Marcel Dekker, New York.

6. Gellin, B. G., and C. V. Broome. 1989. Listeriosis. JAMA 261:13131320.

7. Glass, K. A., D. A. Granberg, A. L. Smith, A. M. McNamara, M. Hardin, J. Mattias, K. Ladwig, and E. A. Johnson. 2002. Inhibition of Listeria monocytogenes by sodium diacetate and sodium lactate on wieners and cooked bratwurst. J. Food Prot. 65:116-123.

8. Juneja, V. K. 2003. Predictive model for the combined effect of temperature, sodium lactate, and sodium diacetate on the heat resistance of Listeria monocytogenes in beef J. Food Prot. 66:804-811.

9. Linton, R. H., W. H. Carter, M. D. Pierson, and C. R. Hackney. 1995. Use of a modified Gompertz equation to model nonlinear survival curves for Listeria monocytogenes Scott A. J. Food Prot. 58: 946-954.

10. Linton, R. H., W. H. Carter, M. D. Pierson, C. R. Hackney, and J. D. Eifert. 1996. Use of a modified Gompertz equation to predict the effects of temperature, $\mathrm{pH}$, and $\mathrm{NaCl}$ on the inactivation of Listeria monocytogenes Scott A heated in infant milk. J. Food Prot. 59:1623.

11. Luchansky, J. B., and J. E. Call. 2004. Evaluation of nisin-coated cellulose casings for the control of Listeria monocytogenes inoculated onto the surface of commercially prepared frankfurters. $\underline{\text { J. Food }}$ Prot. 67:1017-1021.

12. McMahon, C. M. M., A. M. Doherty, J. J. Sheridan, I. S. Blair, D. A. McDowell, and T. Hegarty. 1999. Synergistic effect of heat and sodium lactate on the thermal resistance of Yersinia enterocolitica and Listeria monocytogenes in minced beef. Lett. Appl. Microbiol. 28:340-344.

13. Mead, P. S., L. Slutsker, V. Dietz, L. F. McCaig, J. S. Bresee, C. Shapiro, P. M. Griffin, and R. V. Tauxe. 1999. Food-related illness and death in the United States. Emerg. Infect. Dis. 5:607-625.

14. Murphy, R. Y., T. Osaili, L. K. Duncan, and J. A. Marcy. 2004. Effect of sodium lactate on thermal inactivation of Listeria monocytogenes and Salmonella in ground chicken thigh and leg meat. $\underline{J}$. Food Prot. 67:1403-1407.

15. Porto, A. C. S., J. E. Call, and J. B. Luchansky. 2004. Effect of reheating on viability of a five-strain mixture of Listeria monocytogenes in vacuum-sealed packages of frankfurters following refrigerated or frozen storage. J. Food Prot. 67:71-76.

16. U.S. Department of Agriculture, Food Safety and Inspection Service. 2003. Code of federal regulations, title 9, 430.4. Control of Listeria monocytogenes in post-lethality exposed ready-to-eat products. Available at: http://www.fsis.usda.gov/OPPDE/rdad/FRPubs/97013F.htm. Accessed 22 April 2004.

17. U.S. Food and Drug Administration, Center for Food Safety and Applied Nutrition. 2003. Quantitative assessment of relative risk to public health from foodborne Listeria monocytogenes among selected categories of ready-to-eat foods. Available at: http:// www.fsis.usda.gov/OA/topics/lm.htm. Accessed 15 April 2004. 